Volume 12 Issue 3

August 2021

\title{
San'yas Indigenous Cultural Safety Training as an Educational Intervention: Promoting Anti-Racism and Equity in Health Systems, Policies, and Practices
}

\author{
Annette J. Browne \\ The University of British Columbia, Canada, Annette.Browne@ubc.ca \\ Colleen Varcoe \\ The University of British Columbia, Canada, colleen.varcoe@ubc.ca \\ Cheryl Ward ${ }^{*}$ \\ Indigenous Health, Provincial Health Services Authority, British Columbia, Canada, cward-02@phsa.ca
}




\title{
San'yas Indigenous Cultural Safety Training as an Educational Intervention: Promoting Anti-Racism and Equity in Health Systems, Policies, and Practices
}

\begin{abstract}
The Sạn'yas Indigenous Cultural Safety Training Program is an Indigenous-led, policy-driven, and systems-level educational intervention to foster health equity and mitigate the effects of systemic racism experienced by Indigenous people in health and other sectors. Currently, San'yas is being scaled-up across Canada. This article focuses on the following: (a) the pedagogical underpinnings of San'yas grounded in transformational learning principles and Indigenous knowledges; (b) the scope, reach, and scale-up of San'yas as an explicit anti-racism educational intervention; (c) its unique program delivery approaches; and (d) program evaluation trends. We discuss the insights gained from implementing San'yas over the past decade, which will be relevant for leaders and policy-makers concerned with implementing anti-racism educational interventions as part of broader system transformation.
\end{abstract}

\section{Keywords}

Indigenous people, cultural safety, racism, inequities, health care, health equity, discrimination

Author Note

${ }^{*}$ Dr. Ward is intentionally positioned as the last author to signal her leadership regarding strategies to counteract anti-Indigenous racism in health systems and other sectors.

\section{Creative Commons License}

\section{(c) (1) $9 \Theta$}

This work is licensed under a Creative Commons Attribution-Noncommercial-No Derivative Works 4.0 License. 


\section{Sann'yas Indigenous Cultural Safety Training as an Educational Intervention: Promoting Anti- Racism and Equity in Health Systems, Policies, and Practices}

Structural and interpersonal forms of racism, and other forms of discrimination, continue to shape the health and well-being of Indigenous ${ }^{1}$ Peoples in Canada and globally (Allan \& Smylie, 2015; Bourassa et al., 2004; Browne, 2017; R. Henry et al., 2018; Mackean et al., 2019; McCallum \& Perry, 2018; National Inquiry into Missing and Murdered Indigenous Women and Girls, 2019a; Paradies, 2018; Paradies \& Cunningham, 2009; Public Health Agency of Canada, 2019; United Nations, 2016). Inequitable power relations, colonial assumptions, stereotyping, and negative social attitudes toward Indigenous people endure as influential forces shaping access to care, people's experiences of care, and health outcomes, despite calls and efforts to address health and social inequities (Browne et al., 2016; Dell et al., 2016; Greenwood et al., 2018; Hole et al., 2015; Nelson et al., 2016; Varcoe, Browne, \& Blanchet Garneau, 2019). The recent events in Canada surrounding the tragic death of Ms. Joyce Echaquan (Chadha, 2020; “Joyce Echaquan: Outcry in Canada," 2020; Kirkup, 2020), the investigation into emergency department staff playing "games" in which they would guess blood alcohol levels of Indigenous patients (Turpel-Lafond, 2020), and the decades-long investigation into the death of Mr. Brian Sinclair (Brian Sinclair Working Group, 2017; McCallum \& Perry, 2018) have brought renewed attention to the harms of Indigenous-specific racism.

It is within this context that the Truth and Reconciliation Commission of Canada's (TRC) final report (2015) issued a set of 94 Calls to Action for renewed commitments to the process of reconciliation, defined as necessitating mutually respectful relationships between Indigenous Peoples and nonIndigenous peoples, awareness of the past, acknowledgment of the harms incurred, atonement for the causes, and actions to transform relationships, practices, and policies. Most recently, Reclaiming Power and Place: The Final Report of the National Inquiry into Missing and Murdered Indigenous Women and Girls (National Inquiry into Missing and Murdered Indigenous Women and Girls, 2019b) reinforced the urgent need for Indigenous and non-Indigenous people to work together to mitigate the ongoing effects of Canada's colonial context. In the context of these calls and realities, the $S_{\underline{a}} n^{\prime} \mathbf{y s}^{2}$ Indigenous Cultural Safety Training Program, an Indigenous-led, policy-driven, and systems-level educational intervention, aims to foster health equity and mitigate the intersecting forms of interpersonal and structural racism experienced by Indigenous people in the health care system in Canada.

Rooted in critical anti-racist pedagogy, transformative learning theory, and evidence-based strategies, San'yas is an educational intervention that aims to do the following: (a) build the knowledge, selfawareness, and skills of participants to work more safely and effectively with Indigenous people; and (b)

\footnotetext{
${ }^{1}$ Consistent with accepted terminology used in landmark international reports, the term Indigenous Peoples is used to refer to the diversity of populations throughout the world. In Canada, over 1.7 million people of the total population of approximately 34.5 million (4.9\%) identify as Indigenous (Statistics Canada, 2019), including First Nations, Métis, and Inuit. The term Aboriginal is also commonly used, and the colonial term Indian is still used in federal government policy documents such as the Indian Act. The Indian Act is a Canadian federal law that governs in matters pertaining to Indian Status, Indian bands, and Indian reserves (Indian Act, 1985). This authority has ranged from overarching political control, such as imposing governing structures on Indigenous communities in the form of band councils, to control over the rights of Indigenous Peoples to practice their culture and traditions. While the Indian Act has undergone numerous amendments since it was first passed in 1876, today it largely retains its original form.

2 San'yas is a Kwak'wala word meaning "to know” or "knowing."
} 
support broader organizational and systemic change. San'yas offers both online training and consultation services designed to actively attune participants to the root causes of inequitable power relations and health outcomes affecting Indigenous people, the health and social impacts of antiIndigenous racism, stigma and stereotyping, and strategies for creating more equitable systems of care for Indigenous people in service delivery contexts.

San'yas is currently offered in health authorities and other government agencies in British Columbia (BC) since 2010, in Ontario (ON) since 2013, and in Manitoba (MB) since 2016. Table 1 outlines the range of online, facilitated, interactive training programs, each of which are delivered via an innovative platform of multi-media modules tailored for diverse contexts and participants. Participants are guided through the training programs through a process of facilitated engagement with highly trained educators, learning activities, individual and group discussions, and access to Indigenous Elders and Knowledge Keepers, and are provided with facilitated opportunities to generate strategies for implementing cultural safety in ways that align with participants' varied work and service sector contexts. To date, over 126,000 people across Canada have completed at least one of the online San'yas training programs, and San'yas continues to be adapted for widespread scale-up in diverse sectors, including the public service sector, child welfare services, correctional services, and elsewhere.

The purpose of this article is to describe the evolution and aims of San'yas, its theoretical grounding in critical anti-racist pedagogy and transformative learning, and the impacts and policy implications of its uptake in Canada. This analysis provides background and context regarding the development of San 'yas for those undergoing the training, and for policy- and decision-makers in health authorities, institutions, organizations, and health profession regulatory bodies who are considering scale-up and adaptations of anti-racism training in various jurisdictions nationally and internationally. Our aim is to contribute to the ongoing dialogue in Canada and internationally regarding system-level efforts to integrate cultural safety within organizations with the explicit aim of promoting anti-racism and health equity in systems, policies, and practices. The article begins with a discussion of the effects of interpersonal and systemic racism on First Nations, Métis, and Inuit. Our analysis focuses on: (a) the pedagogical underpinnings of Sann'yas grounded in transformational learning principles and Indigenous knowledges, (b) the scope, reach and scale-up of San'yas as an explicit anti-racism educational intervention, (c) its unique program delivery approaches, and $(\mathrm{d})$ program evaluation trends. The article ends with a discussion of the insights gained from implementing San'yas over the past decade, which will be relevant for leaders and policymakers concerned with implementing anti-racism educational interventions as part of broader system transformation. 
Browne et al.: Sạn'yas Indigenous Cultural Safety Training

Table 1. San'yas Core Indigenous Cultural Safety (ICS) Online Training and Advanced Training Programs

\begin{tabular}{l} 
Core training \\
\hline \multicolumn{1}{c}{ Foundations } \\
Explores foundational issues related to cultural safety, \\
including topics such as culture and Indigenous people \\
in Canada, colonization and its legacies, images of \\
Indigenous people, and engaging in cultural safety at \\
work
\end{tabular}

\section{Health}

Builds on the foundational aspects of cultural safety described above with a specific focus on health care issues for health care professionals working with Indigenous people; not intended to teach individual Nation-specific content but rather be a foundation for understanding the broader issues impacting services for Indigenous people

\section{Mental health}

Builds on the foundation provided in Core Health with a specific focus on mental health issues for professionals working with Indigenous people; the goal is to improve access to mental health services and mental health outcomes for Indigenous people; intended as introductory training and is supplemented by the Nation and region-specific training provided by regional health authorities or Indigenous groups

\section{Child welfare}

Focuses specifically on child welfare issues for professionals working with Indigenous children and families; intended as introductory training to be supplemented by the Nation- and region-specific training provided by Indigenous communities or groups

\section{Justice}

Focuses on core components of cultural safety that apply across diverse justice settings; intended as an introductory training and is supplemented by the Nation- and region-specific training provided by Indigenous groups
People working in non-health-related fields such as justice, child and family services, education, business, and government

People working in health care fields; intended as introductory training and is supplemented by the Nation- and region-specific training provided by regional health authorities or Indigenous groups

People working in the mental health field

Professionals working with Indigenous children and families; relevant to those who work in child and family services

People working within the justice system (law clinics, police, court houses, sheriff's office, judiciary, and correctional facilities) who work with Indigenous people or others who wish to increase their knowledge, awareness, and skills 
Table 1. San'yas Core Indigenous Cultural Safety (ICS) Online Training and Advanced Training Programs (continued)

\begin{tabular}{ll}
\hline \multicolumn{1}{c}{ Advanced training } & \multicolumn{1}{c}{ Primary audiences } \\
\hline \multicolumn{1}{c}{ From Bystander to Ally } \\
$\begin{array}{l}\text { Designed to help participants explore how to become } \\
\text { an effective ally when racism, bias, or stereotyping is }\end{array}$ & $\begin{array}{l}\text { People who have completed one of the core training } \\
\text { programs at least six months prior }\end{array}$ \\
impacting the service an Indigenous person is & \\
receiving; participants learn about ways to assess & \\
situations that may have elements of bias or racism and & \\
then develop strategies to use that can be effective in & \\
the participants' local context &
\end{tabular}

Note. Adapted from Sann'yas Indigenous Cultural Safety Training (n.d.). The tailored modules for all programs vary in length depending on target audience, service sector, and workplace context. Learning is self-paced, and typically occurs over an 8 -week period. Depending on participants' learning styles, the program requires approximately 8 to 10 hours to complete. In addition, Indigenous-only Core Health and Mental Health training programs are offered for participants who self-identify as Indigenous.

\section{Background}

In recent decades, there has been an expanding body of evidence demonstrating how persistent assumptions about "race" 3 as a social category and racism as a social process have profound harmful effects on health, access to health care, and quality of life (Bailey et al., 2017; Krieger, 2020; Williams et al., 2019). Research continues to deepen understandings of the pathways by which racial discrimination negatively impacts health, including, for example, through longstanding and entrenched inequities within child welfare and criminal justice systems; ongoing economic and social deprivation; explicit and inexplicit constraints on access to resources such as health care, housing, and related social determinants of health; the direct physiological and psychological effects of stress arising from interactions that are perceived to be discriminatory; and the tense social dynamics that can result from the vigilance required

\footnotetext{
${ }^{3}$ Race is conceptualized as a:

A socially constructed category used to classify humankind according to common ancestry and reliant on differentiation by such physical characteristics such as color of skin, hair texture, stature, and facial characteristics. The concept of race has no basis in biological reality and, as such, has no meaning independent of its social definitions. (F. Henry et al., 2010, p. 351)

Krieger (2014) defines discrimination as "a socially structured and sanctioned phenomenon, justified by ideology and expressed in interactions among and between individuals and institutions that maintains privileges for members of dominant groups at the cost of deprivation for others" (p. 650), with racial discrimination being enacted on the basis of race. The notion of democratic racism is useful for explaining how Canadians can hold negative views about particular groups of people, while at the same time espousing liberal democratic principles of equality, tolerance, fairness, and the existence of an equal playing field, epitomized in the phrase, "We treat everyone equally" (F. Henry et al., 2010). Racialization refers to the social process by which people are labeled according to particular physical characteristics or arbitrary ethnocultural or racial categories, and then dealt with in accordance with beliefs related to those labels. Racialization is not synonymous with racist but relates to the discourses that are drawn on to interpret the behaviors or characteristics of people who are seen as being from a "different" so-called racial or ethnocultural group (Browne et al., 2009, p. 168). These discourses assume "that 'race' is the primary, natural, and neutral means of categorization, and that the groups are distinct also in behavioral characteristics, which result from their 'race'" (Ahmad, 1993, pp. 18-19). Racializing processes, policies, and practices have been central to the colonial project of defining, categorizing, and managing Indigenous Peoples (Browne, 2005).
} 
in anticipation of racial discrimination (Bailey et al., 2017; Hansen \& Metzl, 2019; Krieger, 2014, 2020). These applications of eco-social theory and life course perspectives to analyses of the embodiment of racial inequity help to illuminate the complex intergenerational health and social impacts on families, communities, and populations, including the long-term adverse effects of racialized traumatic experiences on the well-being of future generations (Krieger, 2014; Williams et al., 2019).

The pathways between racism and health illustrate how interpersonal and structural or systemic racism intersect. Interpersonal racism refers to "directly perceived discriminatory interactions between individuals - whether in their institutional roles (e.g., employer/employee) or as public or private individuals (e.g., shopkeeper/shopper)" (Krieger, 2014, p. 650). Structural racism, often used interchangeably with systemic or institutional racism:

Refers to the totality of ways in which societies foster racial discrimination through mutually reinforcing systems of housing, education, employment, earnings, benefits, credit, media, health care, and criminal justice. These patterns and practices in turn reinforce discriminatory beliefs, values, and distribution of resources. (Bailey et al., 2017, p. 1453)

The intersections between interpersonal and structural racism have important implications in the Canadian context. Canada's colonial structure, initiated historically and continually operating through dominant institutions and legislative frameworks such as the Indian Act, has generated and perpetuated widely held stigmatizing and pejorative ideas about Indigenous people, resulting in negative normative beliefs (stereotypes) and attitudes (prejudice), and the differential treatment of Indigenous people at an individual level and within social institutions. The evidence-based literature continues to elucidate the extent to which racialized assumptions about Indigenous people actually organize health care providers' practices, as well as organizational and institutional policies, discourses, and norms (Allan \& Smylie, 2015; Browne et al., 2016; Dion Stout \& Downey, 2006; Fiske \& Browne, 2006; Greenwood et al., 2018; Kelm, 1998; Kirmayer et al., 2014; Maxwell, 2014; National Inquiry into Missing and Murdered Indigenous Women and Girls, 2019; O’Neil et al., 1998; Razack, 2015). For example, one of the most ubiquitous and harmful stereotypes pervading Canadian social consciousness is founded on colonizing images of Indigenous people as being more prone to alcohol use than other Canadians, despite the body of evidence refuting this myth and pointing to the use of alcohol as a tool of colonization (British Columbia Provincial Health Officer, 2002; Razack, 2015; Tait, 2009). Stereotypes about Indigenous people "getting everything for free" continue to shape perceptions within the health care sector about Indigenous people as being undeserving recipients of care (Browne, 2017; Firestone et al., 2019; Kitching et al., 2019; McCallum \& Perry, 2018; Monchalin et al., 2019). Enduring colonizing images and discourses about Indigenous women as irresponsible and incompetent parents continue to underpin the State's widespread removal of Indigenous children from their families and communities (Anaya, 2014; National Inquiry into Missing and Murdered Indigenous Women and Girls, 2019a, 2019b; Sinha \& Kozlowski, 2013; TRC, 2015). These sociopolitical dynamics have had profoundly disruptive effects on social and intergenerational relations, as evidenced through the disenfranchisement of Indigenous 
women, substandard and overcrowded living conditions on reserves, ${ }^{4}$ lack of affordable housing in urban areas, and everyday experiences of gender-based racist violence (Maxwell, 2014; National Inquiry into Missing and Murdered Indigenous Women and Girls, 2019a, 2019b; Varcoe, Ford-Gilboe, et al., 2019).

Despite efforts toward enhancing cultural sensitivity in health care, negative social attitudes toward Indigenous people continue to shape experiences within the health system (McCallum \& Perry, 2018; Turpel-Lafond, 2020). Experiences of discrimination are further amplified in the context of stigmatizing conditions such as chronic pain, arthritis, diabetes, and HIV (Craig et al., 2020; Public Health Agency of Canada, 2019). Life expectancy continues to be consistently lower among First Nations and Inuit, the health status of off-reserve Indigenous populations across Canada is shown to be declining, and Indigenous families and communities continue to live with disproportionately high rates of infant mortality, diabetes, violence against Indigenous women, and exposure to environmental contaminants (Greenwood et al., 2018; National Inquiry into Missing and Murdered Indigenous Women and Girls, 2019a, 2019b; Public Health Agency of Canada, 2019; Public Health Agency of Canada \& PanCanadian Public Health Network, 2018; Wrathall et al., 2020). Poorer cancer-related health outcomes for Indigenous people in Canada reflect both barriers to screening and longer time to diagnosis and treatment, representing one of myriad ways in which inequities become further entrenched with profound impacts on the health of individuals, communities, and populations (Horrill et al., 2019; Lavoie et al., 2016). This has prompted calls for national cancer control plans to enhance their focus on cultural safety where the sociopolitical lived realities of generations of Indigenous people have led to the cancer inequities which are deepening today (Sayani, 2019).

These indicators, while useful for highlighting health and social inequities, are largely deficit-based and tend to inadequately incorporate Indigenous people's experiences of health and wellness or their experiences within the health care system (Public Health Agency of Canada \& Pan-Canadian Public Health Network, 2018). Moreover, these indicators have the potential to contribute to pathologizing stereotypes and to reinforcing discriminatory attitudes toward Indigenous people if they are presented without adequate explanatory context about the structural factors that impact Indigenous communities and populations (Dion Stout, 2012). Thus, for health system responses to be effective, programs, planning, and actions must be Indigenous-specific and community-driven, taking into consideration the ways in which Indigenous knowledges, cultural revitalization, self-determination, and political mobilization are operating to support Indigenous people's health and well-being (Dion Stout, 2012; Greenwood et al., 2018). More specifically, in relation to Indigenous people's health and the need for enhanced professional development and training, the TRC Call to Action \#57 states:

We call upon the federal, provincial, territorial and municipal governments to provide education to public servants on the history of Aboriginal peoples, including the history and legacy of residentials schools, the United Nations Declaration on the Rights of Indigenous Peoples, Treaties and Aboriginal rights, Indigenous law, and Aboriginal-Crown relations. This will

\footnotetext{
${ }^{4}$ In Canada, the reserve system is governed by the Indian Act, which designates First Nations bands and people, referred to in the context of the Indian Act as "Indians." According to the Indian Act, an Indian Reserve is a tract of land set aside under the Act and treaty agreements for the exclusive use of an Indian band. Band members possess the right to live on reserve lands, and band administrative and political structures are frequently located there. Reserve lands are not strictly "owned" by bands, rather they are held in trust for bands by the Crown. The Indian Act grants the federal Minister of Indigenous Services (formerly, part of Indigenous and Northern Affairs Canada) authority over much of the activity on reserves.
} 
require skills-based training in intercultural competency, conflict resolution, human rights, and anti-racism. (TRC, 2015, p. 218)

San'yas is explicitly designed and is currently being taken up across Canada as a systems-level response to countering systemic racism and other forms of discrimination as one pathway to fostering health equity in relation to Indigenous people.

\section{Analysis: Embedding Cultural Safety in Health Systems Transformation}

\section{Theoretical Orientation-Critical and Indigenous Perspectives}

Cultural safety, as taken up in Sann'yas as a health system and policy response, is firmly positioned within the paradigms of critically oriented theoretical perspectives, notably critical race theories and postcolonial theoretical perspectives, and Indigenous epistemologies. Critical theoretical perspectives are fundamentally concerned with issues of power and social justice, and, more specifically, with the pervasiveness of inequitable power relations and structures within society (Varcoe, Browne, \& Blanchet Garneau, 2019). More specifically, the San'yas curriculum is informed by critical race theories, which are inclusive of a diverse range of disciplinary perspectives including those used by legal scholars to focus on racist discourses and expressions embedded in and reflective of differing historical eras and their ongoing manifestations, and strategies for counteracting their influence in social systems and practices (Donnor \& Ladson-Billings, 2018; Essed, 2002; F. Henry et al., 2010; van de Kleut, 2011). Postcolonial theoretical perspectives draw attention to the importance of critically interrogating the colonial past and its ongoing impact in today's context, including examining the experiences of colonialism and their continuing manifestations. Postcolonial theories offer the deliberate decentering of dominant culture, centering the perspectives of those who have been marginalized by political and social forces, and understandings of how conceptualizations of race, racialization, and culture are constructed within particular historical and current neocolonial contexts (Browne et al., 2005, 2007; Gandhi, 1998; McConaghy, 2000; Reimer-Kirkham \& Anderson, 2002). Indigenous epistemologies and perspectives provide an essential vantage point from which to understand issues of racism and discrimination in Canada, and the salience of history, identity, and Indigenous-State relations in shaping ongoing policy and system-level responses (Coulthard, 2014; Ermine, 2007; McIvor, 2004; Monture-Angus \& Turpel, 1995). Indigenous knowledges tend to be grounded in relational epistemologies emphasizing the intersections among historical, economic, social, and cultural contexts, as well as issues of identity, agency, and self-determination, and they are intended to counterbalance the fragmented and individualistic approaches to analyses of racism and discrimination that often dominate Western thinking (Battiste, 2000; Battiste et al., 2002; Kovach, 2018).

Critical pedagogy, framed in relation to critical theoretical perspectives, is an approach to teachinglearning-curricular design founded on certain basic assumptions, such as all thought is fundamentally mediated by power relations that are social and historically constituted, and facts cannot be isolated from the domain of values or understood apart from their ideological inscription (Kincheloe et al., 2018). Anti-racist pedagogy, conceptualized as one approach or application of critical pedagogy, implies the need to teach with a specific social and political intent, and with a transformative impetus, which is to act upon individual and systemic discrimination (Blanchet Garneau et al., 2017). In the context of antiracist pedagogy, the aim toward transformative learning refers to supporting learners to explicitly 
identify, challenge, and change the structures that perpetuate and keep systemic racism in place (Calliste \& Dei, 2000). In the Canadian context, for example, the Ontario Human Rights Commission (2005) described anti-racist training as focused on "producing an understanding of what racism is and how it can be challenged. Anti-racism training aims to achieve not only a change in individual attitudes, but also a transformation of individual and collective practices" (p. 51). These perspectives have guided how San'yas has been scaled up, taken up, and embedded into provincial anti-racist policy initiatives.

Indigenous knowledges and perspectives are foundational to San'yas as an Indigenous-led program developed in partnership with Indigenous leaders, academics, curriculum writers, and editors. The development of San'yas as a health systems initiative started in 2009 in response to two major national commissions in Canada: the Royal Commission on Aboriginal Peoples (1996) and the landmark Transformative Change Accord in British Columbia ${ }^{5}$ (British Columbia Assembly of First Nations et al., 2005). Led by Cheryl Ward (Kwakwaka' wakw), executive director of Indigenous Health at the BC Provincial Health Services Authority (PHSA), and Leslie Varley (Nisga'a), former director of Indigenous Health at the BC PHSA, extensive community engagement with Indigenous Elders, leaders, and community members provided the basis for the pedagogical orientation, curriculum design, and learning approaches used in San'yas.

Throughout its evolution, San'yas has been oriented around the central concept of cultural safety because of its explicit focus on power imbalances and inequitable social relationships in health care, the inter-related problems of culturalism ${ }^{6}$ and racialization, the strength and resilience of Indigenous people, and commitment to mitigating the negative impacts of health and social inequities (Ramsden, 1993, 2000). Originally conceptualized in New Zealand in the early 1990s by Māori nurse-leaders and educators, cultural safety was developed as an organizing concept "to reorient the training of health professionals towards a more critical understanding of colonial structures and their impacts on contemporary Māori” (Dyck \& Kearns, 1995, p. 141). As a policy orientation for health care that has broad applications across sectors and as a concept that is legislated as a basic requirement in nursing and medical professional education in New Zealand, cultural safety has continued to evolve as a health systems directive, not only in relation to Māori people, but as a political discourse that shapes health care design and delivery (Curtis et al., 2019; Vernon \& Papps, 2015).

In the Canadian context, as a pluralist society that legislates multiculturalism in all aspects of policy, cultural safety has been taken up as a pragmatic tool for moving health care practices and policies

\footnotetext{
${ }^{5}$ British Columbia Assembly of First Nations et al. (2005) reported:

In November 2005, the Province of British Columbia, the First Nations Leadership Council, and the Government of Canada signed a historic agreement entitled the Transformative Change Accord. The Accord recognizes the need to strengthen relationships on a government-to-government basis, and affirms the parties' commitment to achieve three goals:

1. Close the gaps between First Nations and other British Columbians in the areas of education, health, housing and economic opportunities over the next 10 years;

2. Reconcile Aboriginal rights and title with those of the Crown; and

3. Establish a new relationship based on mutual respect and recognition. (p. 2)

${ }^{6}$ Culturalism refers to the process of viewing people through the lens of culture, defined narrowly as shared values, beliefs, and practices, and often conflated with ethnicity. In this process, "culture," thus defined, operates as the primary explanation for why certain people or groups experience various health, social, or economic problems, such as poverty, substance use, or low birth weight (Browne \& Varcoe, 2006; Browne et al., 2009; Varcoe et al., 2013).
} 
beyond a focus on cultural sensitivity in order to address inequitable power relations, Indigenousspecific and other forms of racism and stigma, and the ongoing effects of historical injustices more actively on health and health care (First Nations Health Authority, 2016). As we have discussed elsewhere, the analytical leverage of cultural safety lies in its potential to shift attention away from presumed cultural differences as barriers to effective health care so as to refocus attention on the culture of health care as the site for transformation (Browne, 2017; Browne et al., 2016; Varcoe, Browne, \& Kang, 2019). These applications of cultural safety are in no way intended to diminish the value of Indigenous cultural practices, worldviews, or knowledges as key determinants of health. Rather, from the vantage point of cultural safety, culturally specific knowledges and practices, including connections to identity, community, Elders, ${ }^{7}$ and language, are framed as fundamental to health and healing, and as central to the project of achieving more equitable health policy and system transformations (First Nations Health Authority, 2016; Hadjipavlou et al., 2018; TRC, 2015; Varcoe, Ford-Gilboe, et al., 2019). Given these features of cultural safety, and in response to the TRC's Calls to Action, all health authorities and regulatory bodies in British Columbia have committed to "hardwire" cultural safety into health policies and systems by signing onto a Declaration of Commitment on Cultural Safety and Humility in Health Services for First Nations and Indigenous People in British Columbia (First Nations Health Authority, 2017). This initiative, co-led by the First Nations Health Authority in partnership with all BC Health Authority chief executive officers and all BC health profession regulatory leaders, includes resources designated to supporting large proportions of the health, social, and public service workforce to complete San'yas; various organizations either mandate or strongly encourage their employees to complete $S_{\text {ann }}$ yas, which is accredited by numerous organizations. ${ }^{9}$

\section{Scope, Reach, and Scale-Up of San'yas as an Educational Intervention}

Originally designed as an educational intervention to foster health equity within the health care sector, over the past decade, provincial governments, ministries, and health authorities across Canada have embedded Sann'yas as an essential component of their overall health and social service system transformations. The scope of San'yas is now expanded beyond its initial mandate as a health workforce initiative; Sann'yas delivers consultations and tailored learning modules created and adapted for implementation in a wide range of health and social service sectors across Canada, including child welfare, people working in the justice system including correctional and police services, and mental health. To date, large proportions of the health, social service, and public sector workforce members in $\mathrm{BC}$ and Ontario have completed the San'yas training programs - including policymakers, executive leaders, administrative staff, and all levels of workers involved in direct service delivery. For example, since its initial implementation in BC in 2010, over 56,000 people have completed at least one of the Sann'yas training programs, including those working in health, mental health, child welfare, and justice

\footnotetext{
${ }^{7}$ Elders are recognized by their communities for possessing common qualities that are highly valued-leadership, accumulated wisdom, compassion, community devotion, and dedication to personal healing (Hadjipavlou et al., 2018; Royal Commission on Aboriginal Peoples, 1996).

${ }^{8}$ The First Nations Health Authority, created in 2014, is the only Indigenous province-wide health authority in Canada.

${ }^{9}$ For example, the BC College of Nurses and Midwives encourages all nurses to complete the Core Health training part of a broader strategy for making the health system more culturally safe for Indigenous Peoples. The Core Health and Mental Health training programs meet the accreditation criteria of the College of Family Physicians of Canada, the Royal College of Physicians and Surgeons of Canada, and the Canadian Counselling and Psychotherapy Association, among others. The programs are also certified for credits required by the Canadian College of Health Leaders.
} 
sectors. Starting in 2013 in Ontario, Indigenous leaders and educators partnered with San'yas to develop Ontario-specific online training courses, with over 70,000 people having completed courses. In July 2016, the Ontario Ministry of Child and Youth Services launched a tailored San'yas training program for all Ministry employees after customizing the program through extensive engagement with the Indigenous Advisory Circles and Ontario Indigenous partners.

Currently, San'yas is being implemented as a highly accessed online anti-racism training platform in the Ontario Public Service (OPS). The extensive scale-up of San'yas in Ontario reflects a province-wide anti-racism policy "to build a more inclusive society, and work to identify, address and prevent systemic racism in government policy, legislation, programs and services" (Government of Ontario, 2016, para. 1). The Ontario anti-racist policy directive intersected with two other policy directives: the Ontario government's response to the TRC's Call to Action \#57, and the Ontario government's long-term strategy to address violence against Indigenous women (Government of Ontario, 2018). San'yas was selected as the OPS training platform "because it addresses the pervasive effects of colonization, how racist attitudes and biases contribute to low socio-economic and health indicators across Indigenous populations, and how the same prejudices perpetuate high rates of violence against Indigenous women and girls" (Government of Ontario, 2018, p. 13). As a result, the San'yas Core Foundations course is currently being delivered as a mandatory cultural safety and anti-racist training program ${ }^{10}$ across the OPS, inclusive of over 60,000 public servants working in areas as wide-ranging as correctional services, long-term care, child welfare, and community and social services.

Adaptations to the Sann'yas curriculum to optimize relevancy in Ontario and Manitoba have been designed in partnership with local Indigenous advisory committees to reflect region-specific sociopolitical and geographical contexts and diverse workplace settings. This has required adaptations, vetting, and customizations of San'yas to be relevant to local contexts through the involvement of Indigenous advisory circles including community and advocacy organizations; First Nations, Métis, Inuit, Elder, and youth representatives; policy leaders; academics; and public servants. These strategies have evolved as best practices for adaptations in other sectors and jurisdictions and serve as foundational to integration and scale-up efforts. The successes in implementation are attributable to the extensive network of relations and partnerships the San'yas program leads have developed, the adaptability of the approaches, the systematic approaches to content and process development, and the program delivery approaches described below.

\section{Program Delivery Approaches}

The Sann'yas online training programs (shown in Table 1) utilize a unique platform that offers a blended model of learning, including facilitated, interactive, self-paced modules delivered via an online classroom environment with active engagement of participants within cohorts; asynchronous discussion board activities; reflective journaling; and other activities. Participants are guided through the modules by

\footnotetext{
${ }^{10}$ Sann'yas Core training has been accredited by professional organizations in Ontario, including the Law Society of Ontario's (LSO) Continuing Professional Development requirement for Professionalism Hours that focus on advancing "equality, diversity and inclusion" (EDI). The LSO grants accreditation to EDI training that focuses on, inter alia, "understanding power and privilege, unconscious bias or cultural homophily," the "impact of daily verbal, behavioral and environmental indignities," and "how to prevent and address discrimination and harassment" (Law Society of Ontario, n.d., Section 6.0).
} 
specialized teams of Indigenous and non-Indigenous educators, ${ }^{11}$ who have expertise in adult learning principles, anti-racist pedagogy, cultural safety, and Indigenous people's health. The facilitators work in teams to provide both standardized learning activities and personalized, tailored, one-to-one engagement with learners. In the process, individualized learning opportunities are created to explore and hold up for scrutiny deeply held beliefs and attitudes, pervasive public discourses pertaining to Indigenous people, the current impact of health and social policies on Indigenous people's health and well-being, and the health and social impacts of structural and interpersonal racism and other forms of discrimination. In alignment with anti-racism educational principles, the San'yas facilitation model is aimed at specific learners positioned and acting within systems, institutions, and structures.

In keeping with the dominance of culturalism as an ideology and in partial consequence of embedding the word "cultural" in cultural safety, San'yas participants frequently report that they expect to learn primarily about Indigenous cultures, practices, and differences from the dominant Euro-Canadian culture. Even in the New Zealand context, where cultural safety is part of the lexicon in basic nursing education, it has been challenging to maintain the critical theoretical origins that gave rise to the concept of cultural safety (Downing \& Kowal, 2011; Downing et al., 2011; Ramsden, 2000, 2002; Vernon \& Papps, 2015). As Ramsden (2000) explained in the New Zealand context, "the name remained a source of confusion to many. The popular understanding of culture as ethnicity only led to simplistic notions of cultural checklists avoiding the complex power relationships which the safety factor was intended to address" (p. 173). While San'yas includes content and learning activities, and sensitizes participants to culturally specific content, the goal is to contextualize culturally specific content within the overall critical foundation of San'yas. Facilitators actively and intentionally shift learners' attention away from presumed differences between Indigenous cultures and the dominant Euro-Canadian culture as a barrier or source of the problem. Instead, facilitators refocus attention on power dynamics and inequities and on the dominant organizational characteristics of the health, social service, and government sectors in which they work as the site for critical reflection and transformation.

Mounting an anti-racism educational intervention such as San'yas is inherently challenging because it requires engagement in dialogues regarding racialization; race-based privilege; systemic racism; power inequities; and the role of public institutions, policies, and practices in sustaining inequities. The potential for learners to experience discomfort, guilt, defensiveness, and resistance when asked to explore the implications of relative privilege and disadvantage is widely recognized in the educational literature. In health profession education contexts, for example, research shows that drawing attention to the assumptions and misconceptions that contribute to racializing discourses can sometimes incite resentment toward the very people who are vulnerable to these discourses (Browne, 2005; Browne \& Varcoe, 2006; Fernando \& Bennett, 2019; Franklin et al., 2014; Sukhera et al., 2020; Tang \& Browne, 2008; Varcoe, 2006). This potential for reactivity presents significant challenges from a program delivery perspective and requires intentional, expert strategies to pre-empt harms that can arise from backlash or heightened resentments, or from feeling potentially powerless in the face of ongoing structural forces (Calliste \& Dei, 2000; Dei \& McDermott, 2014; Newton \& Soltani, 2017; Roman, 1993; Vallianatos, 2018; Varcoe \& McCormick, 2007). For example, as participants move through the

\footnotetext{
${ }^{11}$ A ratio of 3 facilitators per 25 learners is maintained for all Core training; for the Bystander to Ally Advanced training, the ratio is 5:25. Facilitators are specialized: each focuses their facilitation on different aspects of the curriculum. Learners have opportunities to dialogue with facilitators who identify as Indigenous, or as White or racialized settlers.
} 
learning modules and engage with discussion board activities, a myriad of examples of the oftendisturbing harms experienced by Indigenous people are discussed.

San'yas facilitators are highly skilled in responding constructively to discussions, with the explicit aim of framing context-specific examples in relation to broader systemic issues and preempting the secondary harms that can occur for some learners, including the potential for the content and postings on discussion boards to trigger strong emotional reactions. However, one of the most significant challenges in delivering San'yas as an educational intervention continues to be managing the often-triggering impacts of learning about racism and the ongoing impacts of colonial structures in Canadian society, and the potential for Indigenous participants to experience specific harms related to their personal, family, or community histories.

Sann'yas aims to create safe learning environments for all learners. Diverse learners undertake Sạn'yas, including those with prior commitments to anti-racism and those without; those who have thought about race-based privilege and those who have not; those who identify as Indigenous and those who identify in a diverse range of other ways, including the many who align with dominant Euro-Canadian culture, often identifying as "not having a culture." The training is designed using strengths-based, trauma- and violence-informed ${ }^{12}$ and culturally respectful approaches. Although educational scholars emphasize that the risk of re-traumatization for non-Indigenous students is often minimal because they are less likely to identify with the traumatic experiences of Indigenous people, and may even develop resistance and denial to the trauma narratives (Duthie, 2019; Fernando \& Bennett, 2019), Sann'yas includes triggering warnings for all participants, encourages self-care activities throughout participants' engagement with the program, and promotes the availability of local employee assistance programs for additional supports.

Given that Indigenous participants are most likely to identify with the traumatic experiences of Indigenous people, additional contextual explanations are provided to advise that aspects of the content focus on explicit manifestations of anti-Indigenous racism and stereotypes, and that defensiveness, skepticism, and resistance are often visible in the discussion boards in which non-Indigenous participants are engaged. Indigenous participants are cautioned that the examples and content used in San'yas may reflect their own or their families' life experiences. Efforts to alert Indigenous participants to the potential for re-traumatization are integrated with efforts to ensure ongoing access to Indigenous facilitators, who connect individually with participants during regular check-in sessions. Indigenous participants are also informed of the opportunity to access Indigenous Elders who are available free of charge to provide specific, individualized supports. The option of Indigenous-specific cohorts is also provided.

\footnotetext{
${ }^{12}$ Trauma- and violence-informed approaches are based on understanding that people disadvantaged by systemic inequities (including those resulting from system and interpersonal racism) often experience multiple forms of violence that have ongoing traumatic impacts; recognizing the effects of interpersonal and structural (e.g., poverty, racism) forms of violence as intersecting, with compounding impacts on health; shifting the emphasis from disclosures of traumatic experiences to creating a safe environment, including for those most traumatized (Browne et al., 2018).
} 
Supports, resources, and ongoing training for Sann'yas facilitators are essential to the overall program delivery to ensure that learners are expertly and supportively guided. Facilitators are particularly skilled at multiple learning approaches to move participants beyond narrow preoccupations with individual prejudices and discriminatory actions to examining the ways in which racist discourses, policies, and practices, as well as individual actions, are entrenched and supported (consciously and unconsciously) in institutional structures. Importantly, facilitators are supported with "scripts" that help them identify and respond to the range of common narratives with which people respond in anti-racist training. These purposeful, planned program delivery strategies are critical to ensuring that participants engaging with San'yas experience an overall sense of safety when provided with opportunities to explore individual and institutional racism, and actions aimed at mitigating inequities.

\section{Evaluating Effectiveness}

The outcome of cultural safety has been defined by health authorities, policymakers, and system leaders as an "outcome based on respectful engagement that recognizes and strives to address power imbalances in the health care system, resulting in an environment free of racism and discrimination-where people feel safe when receiving health services" (Oetter \& Johansen, 2017, para. 3). This long-term vision is the horizon toward which San'yas is oriented. As an educational intervention, however, evaluating the effectiveness of Sann'yas necessarily involves assessments of individuals nested within organizations, systems, and policy-sectors - and requires multiple approaches (Coly \& Parry, 2017; Schierhout et al., 2013). For example, assessing trends in individual-level knowledge, attitudes, and behaviours is important to gauge short-term effectiveness, and must be complemented with ongoing monitoring and adaptations to support effective scale-up in diverse organizational settings, including "whole of government" initiatives.

Sann'yas has been evaluated both internally (i.e., for reporting and quality improvement purposes) and externally (i.e., by consultants and research groups). These evaluations, inclusive of its pedagogy, curricula, facilitation model, and day-to-day processes and structures, highlight trends regarding the extent to which San'yas, as an educational intervention, is meeting its aims. Evaluation approaches include analyses of de-identified, aggregated, and anonymized participation metrics (i.e., quantitative data, such as rates of completion and engagement); pre- and post-training questionnaire scores (i.e., qualitative and quantitative survey data, which can be linked to participant demographics); and analyses of themes reflected in participant entries on discussion boards or journals (i.e., qualitative data). Prior to commencing any training programs, Sann'yas participants consent to the use of their anonymized data for the purpose of ongoing program and performance evaluation.

Evaluation data reveal high levels of overall satisfaction and high likelihood of recommending the training. For example, among the more than 28,000 OPS employees who recently completed at least one of the Core training programs, $93.4 \%$ either agreed or strongly agreed ${ }^{13}$ that "I would recommend this course to my colleagues in other professional settings," and $92.8 \%$ agreed or strongly agreed that "I will use what I have learned in this course in my day-to-day work." The approximately $5 \%$ of participants who indicated overall dissatisfaction described, as the two main trends underpinning their ratings, a strong preference for more content on Indigenous cultures and cultural practices, and lack of support

\footnotetext{
${ }^{13}$ Using a five-point Likert scale with response options: strongly disagree, disagree, neither agree nor disagree, agree, or strongly agree.
} 
within their workplaces to address cultural safety. From the perspective of San'yas program leaders, this points to a need to signal the anti-racism underpinnings of San'yas more clearly, and the fact that education alone is insufficient. Efforts to address organizational support are needed.

Across provinces, evaluation data show that San'yas participants demonstrate increased knowledge, awareness, and skills (e.g., enhanced knowledge of colonization; increased awareness of policies, laws, and programs that perpetuate colonialism) and increased ability to identify strategies to integrate their new understanding into their actions and work functions (e.g., enhanced understanding of the importance of ongoing co-development and co-implementation processes; increased ability to identify strategies to enhance inclusion of Indigenous perspectives in their workplaces). Among the Indigenousonly cohorts, many people report that the training supports a connection or deeper understanding of personal, family, and community history, and that revisiting learnings about the history of colonization supports their sense of collective resilience and strength. Among the non-Indigenous participants, a high proportion indicated that they would commit to ongoing learning and to identifying and speaking up against harmful stereotypes at their workplaces, and they identified skills and mechanisms to be able to do so safely. A recurrent pattern is the extent to which participants credit the program with enabling their own critical reflexivity, confidence, and ability to address interpersonal and systemic forms of racism in their respective workplaces (Churchill et al., 2017; Government of Ontario, 2018; Ward, 2018). For example, participants frequently comment on how completing the program helped them to identify and challenge assumptions about Indigenous people in their work settings; respond to inappropriate comments or discriminatory decisions made by colleagues; and re-examine policies or aspects of workplace culture that seem to discriminate against Indigenous people, as reflected in this response:

I can say that in most situations, when I hear negative, stereotyping comments, I've been a passive witness, and as [the facilitator] said, sometimes I do not speak out because I don't know exactly what to say or how it will be received. I think courses like this will empower me to speak up more.

Thematic analyses of narrative responses reflected in learning activities, discussion boards, and posttraining evaluations provide San'yas program leaders, curriculum designers, and facilitators a window into the context of participants' workplace cultures, and the challenges they experience when attempting to work in culturally safe ways. These data show that predictable resistance discourses arise, reflecting broader societal discourses pervasive in health systems and other sectors in Canada. For example, discourses of egalitarianism are commonly reflected in participants' responses, exemplified in statements such as, "I treat everyone the same"; "systemic racism doesn't occur in my setting"; or "we are completely color-blind in my organization." Facilitators are skilled at surfacing and responding to these commentaries, and the interplay between resistance and opportunity.

Evaluations of discussion board entries also reveal patterns with regard to regional variations in the types of harms experienced by Indigenous people, including "hot spots" for harms such as emergency departments (Turpel-Lafond, 2020). Trends in learners' responses point to ongoing policy and systemlevel changes required. These patterns of responses highlight the need for organization-wide strategies to address anti-Indigenous racism and discrimination, including the often-hostile work environments impacting Indigenous employees (Churchill et al., 2017; Herring et al., 2013; Ward, 2018). Ongoing 
evaluations will be needed to understand the role of anti-racism education interventions more fully as part of broader system transformations.

\section{Discussion}

Ongoing evaluations of San'yas show that reactions to the program reflect a predictable continuum from deep appreciation of the insights gained to a high degree of resistance and sometimes negative reactions to key messages (Ward, 2018). These patterns are not unique to San'yas; they reflect a spectrum of responses that tend to follow predictable patterns whenever racism or colonization are addressed in educational training programs (Dei \& McDermott, 2014; Franklin et al., 2014; Newton \& Soltani, 2017; Okun, 2010; Sukhera et al., 2020; Ward, 2018). The key insights gained from evaluating the scale-up of San'yas over the past decade are relevant to anyone in policy or leadership positions who is considering implementing anti-racism educational interventions.

One of the key features of racism is that its structure and ideology can persist in government and institutional policies, shaping and organizing practices and policies within health and social service sectors, even in the absence of individual actors who are explicitly racially prejudiced (Williams et al., 2019). The rich evidence-base conceptualizing systemic racism and its impacts within health systems has yet to be adequately integrated into responsive health-related policies, health system-level responses, or health professional education (Bailey et al., 2017; Williams et al., 2019; Wyatt et al., 2016). Policy and system-level responses, including educational interventions, therefore continue to be needed regardless of the whether people "accept" the inseparability of interpersonal and institutional racism or not.

Educational interventions alone, however, cannot transform systems, and shifting knowledge, attitudes, and behaviours of individuals is not sustainable without organizational supports, policy directives, accountability mechanisms, and whole-system actions. Health authorities, government sectors, organizations, and institutions cannot, therefore, view San'yas as a stand-alone program; commitments to addressing anti-Indigenous racism and improving health care for Indigenous people will require fullscale policy and organizational transformations. The current trend of writing cultural safety into provincial policies and strategic plans represents an important beginning step toward the broader goal of enhancing health, health care, and social equity for Indigenous Peoples. For example, procuring San'yas for scale-up in the public service sector has allowed the Ontario government to leverage existing investments made by various ministries, and by the $\mathrm{BC}$ government, to avoid duplication of effort by enabling the use of a pre-existing online platform, and to ensure educational consistency.

Locally tailored guidelines will be needed to support the integration, tailoring, and evaluation of cultural safety initiatives and actions, including minimum requirements for maintaining ongoing integration and tailoring within agencies, organizations, institutions, and sectors. Organizational integration and tailoring refer to the processes that can be put in place to support participatory approaches among all levels of staff in an organization to foster shifts in practices and policies to address the aims of cultural safety-tailored to local community contexts, populations served, and organizational priorities (Browne et al., 2015, 2018). The notion of integration, for example, might include ongoing discussions at multiple levels - including executive, leadership, administrative, and direct care staff - to consider implications and accountability mechanisms for enacting cultural safety and countering discrimination in local 
contexts. Tailoring refers to the creation of locally relevant structures and processes to support shifts, actions, or change initiatives.

Resources must be devoted to developing guidelines and strategies to assist leaders within organizations to address and respond to the inevitable discomforts, disruptions, and often secondary traumas that can result when engaging with issues regarding racism and other forms of discrimination, the root causes of health and social inequities, and policies and practices that shape Indigenous people's experiences and outcomes. The "live" facilitation aspect of program delivery will require adequate resourcing as scale-up of San'yas continues in various contexts. Participants will need to be continually assessed with regard to triggering, secondary traumas, backlash, and moral distress — and strategies will need to be implemented to support participants in constructive ways (Turpel-Lafond, 2020).

Also needed are robust evaluation strategies that can account for the complexities of measuring the contributions of San'yas as one component of broader system responses. These might include locally relevant benchmarks; equity-oriented surveys of patients' experiences of care (beyond conventional patient satisfaction measures); measures of everyday experiences of discrimination and discrimination in health care settings, adapted for diverse settings; policy document review processes; observational methods within health care settings; surveys of staff confidence levels related to anti-racist approaches; and analyses of existing administrative data using a health equity lens (Browne et al., 2018; Ford-Gilboe et al., 2018; Varcoe, Bungay, et al., 2019). Recently, the effectiveness of Sann'yas as a component embedded within a larger multi-component organizational health equity intervention was studied as part of implementation research conducted in primary health care clinics in Canada. In that study, staff reported an overall increase in confidence related to their ability to deal with biases, racism, and other forms of discrimination in clinical settings (Browne et al., 2018). The research also showed that equityoriented care, with cultural safety being a key dimension, predicted better health outcomes among patients impacted by significant intersecting inequities (Ford-Gilboe et al., 2018). Further research is needed to continue to generate evidence regarding the efficacy of anti-racism educational programs, such as San'yas, that are embedded within complex, multi-level interventions. Future evaluation strategies must also consider the influence of corporate, managerial, and efficiency pressures, and their influence on anticipated outcomes, and consider the length of time that may be required to fully assess effectiveness.

Recognizing the known limitations of anti-racism educational interventions in affecting sustained behaviour and policy change, and in the face of continued system-level factors and social determinants that significantly impact the health of Indigenous populations, educational efforts must be integrated within larger, multi-level change processes. Redressing racism as it pertains to Indigenous people will continue to require multiple approaches, organizational- and institutional-policy directives, accountability mechanisms, and interventions that can be maximally disruptive of systemic racism and stigmatizing discourses about Indigenous people. 


\section{References}

Ahmad, W. I.-U. (Ed.) (1993). Making Black people sick: 'Race', ideology and health research. Open University Press.

Allan, B., \& Smylie, J. (2015). First Peoples, second class treatment: The role of racism in the health and well-being of Indigenous Peoples in Canada. http://www.wellesleyinstitute.com/wpcontent/uploads/2015/02/Report-First-Peoples-Second-Class-Treatment-Final.pdf

Anaya, J. (2014). Report of the Special Rapporteur on the Rights of Indigenous Peoples, James Anaya, on the situation of Indigenous Peoples in Canada. https://www.refworld.org/docid/ $\underline{53 \mathrm{eb} 3 \mathrm{~b} 774 . \mathrm{html}}$

Bailey, Z. D., Krieger, N., Agénor, M., Graves, J., Linos, N., \& Bassett, M. T. (2017). Structural racism and health inequities in the USA: Evidence and interventions. The Lancet, 389(10077), 14531463. https://doi.org/10.1016/S0140-6736(17)30569-X

Battiste, M. (Ed.) (2000). Reclaiming Indigenous voice and vision. University of British Columbia Press.

Battiste, M., Bell, L., \& Findlay, L. M. (2002). Decolonizing education in Canadian universities: An interdisciplinary, international, Indigenous research project. Canadian Journal of Native Education, 26(2), 82-95.

Blanchet Garneau, A., Browne, A. J., \& Varcoe, C. (2017). Drawing on antiracist approaches toward a critical antidiscriminatory pedagogy for nursing. Nursing Inquiry, 25(1), e12211. https://doi.org/10.1111/nin.12211

Bourassa, C., McKay-McNabb, K., \& Hampton, M. (2004). Racism, sexism, and colonialism: The impact on the health of Aboriginal women in Canada. Canadian Women Studies, 24(1), 23-29.

Brian Sinclair Working Group. (2017). Out of sight: A summary of the events leading up to Brian Sinclair's death and the inquest that examined it and the interim recommendations of the Brian Sinclair Working Group. https://media.winnipegfreepress.com/documents/Out of Sight Final.pdf

British Columbia Assembly of First Nations, First Nations Summit, Union of British Columbia Indian Chiefs, \& Government of British Columbia. (2005). The Transformative Change Accord: First Nations health plan. Supporting the health and wellness of First Nations in British Columbia. http://www.nccah-ccnsa.ca/docs/social\%20determinates/FirstNationsHealthImplementation Plan_Combo_LowRes.pdf

British Columbia Provincial Health Officer. (2002). Report on the health of British Columbians. Provincial health officer's annual report 2001. The health and well-being of Aboriginal people in British Columbia. https://www2.gov.bc.ca/assets/gov/health/about-bc-s-health-care- 
system/office-of-the-provincial-health-officer/reports-publications/annualreports/phoannual2001.pdf

Browne, A. J. (2005). Discourses influencing nurses' perceptions of First Nations patients. Canadian Journal of Nursing Research, 37(4), 62-87.

Browne, A. J. (2017). Moving beyond description: Closing the health equity gap by redressing racism impacting Indigenous populations. Social Science and Medicine, 184, 23-26. https://doi.org/10.1016/j.socscimed.2017.04.045

Browne, A. J., Smye, V. L., \& Varcoe, C. (2005). The relevance of postcolonial theoretical perspectives to research in Aboriginal health. Canadian Journal of Nursing Research, 37(4), 16-37.

Browne, A. J., Smye, V. L., \& Varcoe, C. (2007). Postcolonial-feminist theoretical perspectives and women's health. In M. H. Morrow, O. Hankivsky, \& C. M. Varcoe (Eds.), Women's health in Canada: Critical perspectives on theory and policy (pp. 124-142). University of Toronto Press.

Browne, A. J., \& Varcoe, C. (2006). Critical cultural perspectives and health care involving Aboriginal Peoples. Contemporary Nurse, 22(2), 155-167. https://doi.org/10.5172/conu.2006.22.2.155

Browne, A. J., Varcoe, C., Ford-Gilboe, M., \& Wathen, C. N., on behalf of the EQUIP Research Team. (2015). EQUIP Healthcare: An overview of a multi-component intervention to enhance equityoriented care in primary health care settings. International Journal for Equity in Health, 14(152). https://doi.org/10.1186/s12939-015-0271-y

Browne, A. J., Varcoe, C., Ford-Gilboe, M., Wathen, C. N., Smye, V., Jackson, B. E., Wallace, B., Pauly, B., Herbert, C. P., Lavoie, J. G., Wong, S. T., \& Garneau, A. B. (2018). Disruption as opportunity: Impacts of an organizational health equity intervention in primary care clinics. International Journal for Equity in Health, 17(1), 154. https://doi.org/10.1186/s12939-018$\underline{0820-2}$

Browne, A. J., Varcoe, C., Lavoie, J., Smye, V., Wong, S., Krause, M., Tu, D., Godwin, O., Khan, K., \& Fridkin, A. (2016). Enhancing health care equity with Indigenous populations: Evidence-based strategies from an ethnographic study. BMC Health Services Research, 16(544). https://doi.org/10.1186/s12913-016-1707-9

Browne, A. J., Varcoe, C., Smye, V. L., Reimer-Kirkham, S., Lynam, M. J., \& Wong, S. T. (2009). Cultural safety and the challenges of translating critically oriented knowledge in practice. Nursing Philosophy, 10(3), 167-179. https://doi.org/10.1111/j.1466-769X.2009.00406.x

Calliste, A., \& Dei, G. J. S. (2000). Power, knowledge and anti-racist education: A critical reader. Fernwood Publishing.

Chadha, E. (2020, November 1). Why it's dangerous to be disabled and Indigenous in Canada. National News Watch. https://www.nationalnewswatch.com/2020/11/01/why-its-dangerous-to-bedisabled-and-indigenous-in-canada/\#.X7RM9GhKhPb 
Churchill, M., Parent-Bergeron, M., Smylie, J., Ward, C., Fridkin, A., Smylie, D., \& Firestone, M. (2017). Evidence brief: Wise practices for Indigenous-specific cultural safety training. http://soahac.on.ca/wp-content/uploads/2015/01/CS_WisePractices_FINAL_11.02.17.pdf

Coly, A., \& Parry, G. (2017). Evaluating complex health interventions: A guide to rigorous research designs. https://academyhealth.org/evaluationguide

Coulthard, G. S. (2014). Red skin, white masks: Rejecting the colonial politics of recognition. University of Minnesota Press. https://doi.org/10.5749/minnesota/9780816679645.001.0001

Craig, K. D., Holmes, C., Hudspith, M., Moor, G., Moosa-Mitha, M., Varcoe, C., \& Wallace, B. (2020). Pain in persons who are marginalized by social conditions. Pain, 161(2), 261-265. https://doi.org/10.1097/j.pain.0000000000001719

Curtis, E., Jones, R., Tipene-Leach, D., Walker, C., Loring, B., Paine, S.-J., \& Reid, P. (2019). Why cultural safety rather than cultural competency is required to achieve health equity: A literature review and recommended definition. International Journal for Equity in Health, 18(1), 174174. https://doi.org/10.1186/s12939-019-1082-3

Dei, G. J. S., \& McDermott, M. (2014). Politics of anti-racism education: In search of strategies for transformative learning (Vol. 27). Springer Netherlands. https://doi.org/10.1007/978-94-007$\underline{7627-2 \quad 1}$

Dell, E. M., Firestone, M., Smylie, J., \& Vaillancourt, S. (2016). Cultural safety and providing care to Aboriginal patients in the emergency department. Canadian Journal of Emergency Medicine, 18(4), 1-5. https://doi.org/10.1017/cem.2015.100

Dion Stout, M. (2012). Ascribed health and wellness, Atikowisi miýw- ${ }^{-}$ay ${ }^{-}$awin, to achieved health and wellness, Kaskitamasowin miýw-a ${ }^{-}$ay $^{-}$awin: Shifting the paradigm. Canadian Journal of Nursing Research, 44(2), 11-14.

Dion Stout, M., \& Downey, B. (2006). Nursing, Indigenous Peoples and cultural safety: So what? Now what? Contemporary Nurse, 22(2), 327-332. https://doi.org/10.5172/conu.2006.22.2.327

Donnor, J. K., \& Ladson-Billings, G. (2018). In K. D. Norman \& Y. S. Lincoln (Eds.), The SAGE Handbook of Qualitative Research ( $5^{\text {th }}$ ed., pp. 195-213). Thousand Oaks, California: SAGE Publishing.

Downing, R., \& Kowal, E. (2011). A postcolonial analysis of Indigenous cultural awareness training for health workers. Health Sociology Review, 20(1), 5-15. https://doi.org/10.5172/hesr. $\underline{2011.20 .1 .5}$

Downing, R., Kowal, E., \& Paradies, Y. (2011). Indigenous cultural training for health workers in Australia. International Journal for Quality in Health Care, 23(3), 247-257. https://doi.org/ $\underline{10.1093 / \mathrm{intqhc} / \mathrm{mzr} 008}$ 
Duthie, D. (2019). Embedding Indigenous knowledges and cultural safety in social work curricula: Commentary on "creating a culturally safe space when teaching Aboriginal content in social work: A scoping review” (Fernando \& Bennett, 2018). Australian Social Work, 72(1), 113-116. https://doi.org/10.1080/0312407X.2018.1534978

Dyck, I., \& Kearns, R. (1995). Transforming the relations of research: Towards culturally safe geographies of health and healing. Health \& Place, 1(3), 137-147. https://doi.org/ 10.1016/1353-8292(95)00020-M

Ermine, W. (2007). The ethical space of engagement. Indigenous Law Journal, 6(1), 193-203.

Essed, P. (2002). Everyday racism: A new approach to the study of racism. In P. Essed \& D. T. Goldberg (Eds.), Race critical theories (pp. 176-194). Blackwell Publishers.

Fernando, T., \& Bennett, B. (2019). Creating a culturally safe space when teaching Aboriginal content in social work: A scoping review. Australian Social Work, 72(1), 47-61. https://doi.org/ $\underline{10.1080 / 0312407 X .2018 .1518467}$

Firestone, M., Syrette, J., Jourdain, T., Recollet, V., \& Smylie, J. (2019). "I feel safe just coming here because there are other Native brothers and sisters": Findings from a community-based evaluation of the Niiwin Wendaanimak Four Winds Wellness Program. Canadian Journal of Public Health, 110(4), 404-413. https://doi.org/10.17269/s41997-019-00192-6

First Nations Health Authority. (2016). FNHA's policy statement on cultural safety and humility. https://www.fnha.ca/documents/fnha-policy-statement-cultural-safety-and-humility.pdf

First Nations Health Authority. (2017). All regulated health professions commit to a safer health system for First Nations and Aboriginal People [Press release]. https://www.fnha.ca/about/news-andevents/news/all-regulated-health-professions-commit-to-a-safer-health-system-for-firstnations-and-aboriginal-people

Fiske, J., \& Browne, A. J. (2006). Aboriginal citizen, discredited medical subject: Paradoxical constructions of Aboriginal women's subjectivity in Canadian health care policies. Policy Sciences, 39(1), 91-111. https://doi.org/10.1007/s11077-006-9013-8

Ford-Gilboe, M., Wathen, C. N., Varcoe, C., Herbert, C., Jackson, B. E., Lavoie, J. G., Pauly, B., Perrin, N. A., Smye, V., Wallace, B., Wong, S. T., \& Browne, A. J. (2018). How equity-oriented health care affects health: Key mechanisms and implications for primary health care practice and policy. Milbank Quarterly, 96(4), 635-671. https://doi.org/10.1111/1468-0009.12349

Franklin, H., Paradies, Y., \& Kowal, E. (2014). Critical evaluation of a program to foster reflexive antiracism. International Journal of Social Science Research, 2(2), 20-46. https://doi.org/ $\underline{10.5296 / i j s s r . v 2 i 2.5619}$

Gandhi, L. (1998). Postcolonial theory: A critical introduction. Columbia University Press. 
Government of Ontario (2016). Anti-Racism Directorate. https://www.ontario.ca/page/anti-racismdirectorate? ga $=1.32535998 .1497629888 .1467298446$

Government of Ontario. (2018). Walking together: Ontario's long-term strategy to end violence against Indigenous women. Year two update-March 2018. https://files.ontario.ca/walking together 2-year progress report web englishv2.pdf

Greenwood, M., Leeuw, S. d., \& Lindsay, N. M. (Eds.). (2018). Determinants of Indigenous Peoples' health in Canada: Beyond the social ( $2^{\text {nd }}$ ed.). Canadian Scholars' Press.

Hadjipavlou, G., Varcoe, C., Tu, D., Dehoney, J., Price, R., \& Browne, A. J. (2018). "All my relations”: Experiences and perceptions of Indigenous patients connecting with Indigenous Elders in an inner city primary care partnership for mental health and well-being. Canadian Medical Association Journal, 190(20), E608-E615. https://doi.org/10.1503/cmaj.171390

Hansen, H., \& Metzl, J. M. (Eds.). (2019). Structural competency in mental health and medicine: A case-based approach to treating the social determinants of health. Springer. https://doi.org/ $\underline{10.1007 / 978-3-030-10525-9}$

Henry, F., Rees, T., \& Tator, C. (2010). The colour of democracy: Racism in Canadian society (4 ${ }^{\text {th }}$ ed.). Thomas Nelson.

Henry, R., LaVallee, A., Van Styvendale, N., \& Innes, R. A. (Eds.). (2018). Global Indigenous health: Reconciling the past, engaging the present, animating the future. The University of Arizona Press. https://doi.org/10.2307/j.ctv513dtj

Herring, S., Spangaro, J., Lauw, M., \& McNamara, L. (2013). The intersection of trauma, racism, and cultural competence in effective work with Aboriginal people: Waiting for trust. Australian Social Work, 66(1), 104-117. https://doi.org/10.1080/0312407X.2012.697566

Hole, R. D., Evans, M., Berg, L. D., Bottorff, J. L., Dingwall, C., Alexis, C., Nyberg, J., \& Smith, M. L. (2015). Visibility and voice: Aboriginal people experience culturally safe and unsafe health care. Qualitative Health Research, 25(12), 1662-1674. https://doi.org/10.1177/ $\underline{1049732314566325}$

Horrill, T. C., Linton, J., Lavoie, J. G., Martin, D., Wiens, A., \& Schultz, A. S. H. (2019). Access to cancer care among Indigenous Peoples in Canada: A scoping review. Social Science and Medicine, 238, 112495. https://doi.org/10.1016/j.socscimed.2019.112495

Indian Act (R.S.C., 1985, c. I-5). https://laws-lois.justice.gc.ca/eng/acts/i-5/

Joyce Echaquan: Outcry in Canada over treatment of dying Indigenous woman. (2020, September 30). BBC News. https://www.bbc.com/news/world-us-canada-54350027

Kelm, M. E. (1998). Colonizing bodies: Aboriginal health and healing in British Columbia, 1900-50. University of British Columbia Press. 
Kincheloe, J. L., McLaren, P., Steinberg, S. R., \& Monzo, L. D. (2018). Critical pedagogy and qualitative research: Moving to the bricolage. In N. K. Denzin \& Y. S. Lincoln (Eds.), The SAGE Handbook of Qualitative Research (5 ${ }^{\text {th }}$ ed., pp. 236-260). SAGE Publishing.

Kirkup, K. (2020, November 6). Health experts urge Ottawa to amend Canada Health Act to include anti-racism pillar. The Globe and Mail. https://www.theglobeandmail.com/politics/articlehealth-experts-urge-ottawa-to-amend-canada-health-act-to-include-anti/

Kirmayer, L. J., Gone, J. P., \& Moses, J. (2014). Rethinking historical trauma. Transcultural Psychiatry, 51(3), 299-319. https://doi.org/10.1177/1363461514536358

Kitching, G. T., Firestone, M., Schei, B., Wolfe, S., Bourgeois, C., O’Campo, P., Rotondi, M., Nisenbaum, R., Maddox, R., \& Smylie, J. (2019). Unmet health needs and discrimination by healthcare providers among an Indigenous population in Toronto, Canada. Canadian Journal Public Health, 111, 40-49. https://doi.org/10.17269/s41997-019-00242-z

Kovach, M. (2018). Doing Indigenous methodologies - a letter to a research class. In K. D. Norman \& Y. S. Lincoln (Eds.), The SAGE Handbook of Qualitative Research ( $5^{\text {th }}$ ed., pp. 214--234). SAGE Publishing.

Krieger, N. (2014). Discrimination and health inequities. International Journal of Health Services, 44(4), 643-710. https://doi.org/10.2190/HS.44.4.b

Krieger, N. (2020). Measures of racism, sexism, heterosexism, and gender binarism for health equity research: From structural injustice to embodied harm - an ecosocial analysis. Annual Review of Public Health, 41(1), 37-62. https://doi.org/10.1146/annurev-publhealth-040119-094017

Lavoie, J. G., Kaufert, J., Browne, A. J., \& O’Neil, J. D. (2016). Managing Matajoosh: Determinants of First Nations' cancer care decisions. BMC Health Services Research, 16, 402. https://doi.org/10.1186/s12913-016-1665-2

Law Society of Ontario. (n.d.). Accreditation criteria. https://lso.ca/lawyers/enhancingcompetence/cpd-accreditation-for-licensees/accreditation-criteria\#EDI-Criteria

Mackean, T., Baum, F., Fisher, M., \& Friel, S. (2019). A framework to assess cultural safety in Australian public policy. Health Promotion International, 35(2), 340-351. https://doi.org/10.1093/ $\underline{\text { heapro/daz011 }}$

Maxwell, K. (2014). Historicizing historical trauma theory: Troubling the trans-generational transmission paradigm. Transcultural Psychiatry, 51(3), 407-435. https://doi.org/ $\underline{10.1177 / 1363461514531317}$

McCallum, M. J. L., \& Perry, A. (2018). Structures of indifference: An Indigenous life and death in a Canadian city. University of Manitoba Press. https://doi.org/10.1080/02722011.2019. $\underline{1653694}$ 
McConaghy, C. (2000). Rethinking Indigenous education: Culturalism, colonialism and the politics of knowing. Post Pressed.

McIvor, S. D. (2004). Aboriginal women unmasked: Using equality litigation to advance women's rights. Canadian Journal of Women \& the Law, 16(1), 106-136.

Monchalin, R., Smylie, J., \& Nowgesic, E. (2019). “I guess I shouldn't come back here”: Racism and discrimination as a barrier to accessing health and social services for urban Métis women in Toronto, Canada. Journal of Racial and Ethnic Health Disparities, 7, 251-261. https://doi.org/10.1007/s40615-019-00653-1

Monture-Angus, P., \& Turpel, M. E. (1995). Thunder in my soul: A Mohawk woman speaks. Fernwood Publishing.

National Inquiry into Missing and Murdered Indigenous Women and Girls. (2019a). Reclaiming power and place: Executive summary of the final report. https://www.mmiwg-ffada.ca/wpcontent/uploads/2019/06/Executive Summary.pdf

National Inquiry into Missing and Murdered Indigenous Women and Girls. (2019b). Reclaiming power and place: Final report of the National Inquiry into Missing and Murdered Indigenous Women and Girls. https://www.mmiwg-ffada.ca/final-report/

Nelson, S. E., Browne, A. J., \& Lavoie, J. G. (2016). Representations of Indigenous Peoples and use of pain medications in Canadian news media. The International Indigenous Policy Journal, $7(1)$. https://doi.org/10.18584/iipj.2016.7.1.5

Newton, J., \& Soltani, A. (Eds.). (2017). New framings on anti-racism and resistance: Vol. 2. Resistance and the new futurity ( $1^{\text {st }}$ ed.). Sense Publishers. https://doi.org/10.1007/978-94-6351-131-5

O’Neil, J. D., Reading, J. R., \& Leader, A. (1998). Changing the relations of surveillance: The development of a discourse of resistance in Aboriginal epidemiology. Human Organization, 57(2), 230-237. https://doi.org/10.17730/humo.57.2.b7628vwvg7q127m8

Oetter, H., \& Johansen, C. (2017, March 21). Comment: B.C. health professions' pledge to First Nations. Times Colonist. https://www.timescolonist.com/opinion/op-ed/comment-b-chealth-professions-pledge-to-first-nations-1.12409739

Okun, T. (2010). The emperor has no clothes: Teaching about race and racism to people who don't want to know. Information Age Publishing.

Ontario Human Rights Commission. (2005). Policy and guidelines on racism and racial discrimination. http://www3.ohrc.on.ca/sites/default/files/attachments/Policy and guidelines on racism and_racial_discrimination.pdf

Paradies, Y. (2018). Racism and Indigenous health. In Oxford Research Encyclopedia of Global Public Health. Oxford University Press. https://doi.org/10.1093/acrefore/9780190632366.013.86 
Paradies, Y., \& Cunningham, J. (2009). Experiences of racism among urban Indigenous Australians:

Findings from the DRUID study. Ethnic and Racial Studies, 32(3), 548-573.

https://doi.org/10.1080/01419870802065234

Public Health Agency of Canada. (2019). Addressing stigma: Towards a more inclusive health system. The Chief Public Health Officer's report on the state of public health in Canada 2019. https://www.canada.ca/en/public-health/corporate/publications/chief-public-health-officerreports-state-public-health-canada/addressing-stigma-toward-more-inclusive-healthsystem.html

Public Health Agency of Canada, \& Pan-Canadian Public Health Network. (2018). Key health inequalities in Canada: A national portrait. https://www.canada.ca/content/dam/phacaspc/documents/services/publications/science-research/key-health-inequalities-canadanational-portrait-executive-summary/hir-full-report-eng.pdf

Ramsden, I. (1993). Kawa Whakaruruhau. Cultural safety in nursing education in Aotearoa, New Zealand. Nursing Praxis in New Zealand, 8(3), 4-10. https://doi.org/10.36951/ $\underline{\mathrm{NgPxNZ} .1993 .009}$

Ramsden, I. (2000). Cultural safety/Kawa Whakaruruhau ten years on: A personal overview. Nursing Praxis in New Zealand, 15(1), 4-12. https://doi.org/10.36951/NgPxNZ.2000.001

Ramsden, I. (2002). Cultural safety and nursing education in Aotearoa and Te Waipounamu [Doctoral dissertation, University of Wellington]. https://viewer.waireto.victoria.ac.nz/client/viewer/ IE912183/details?dps dvs=1623264044465 161

Razack, S. H. (2015). Dying from improvements: Inquests and inquiries into Indigenous deaths in custody. University of Toronto Press, Scholarly Publishing Division.

Reimer-Kirkham, S., \& Anderson, J. M. (2002). Postcolonial nursing scholarship: From epistemology to method. Advances in Nursing Science, 25(1), 1-17. https://doi.org/10.1097/00012272$\underline{200209000-00004}$

Roman, L. G. (Ed.) (1993). White is a color! White defensiveness, postmodernism and anti-racism pedagogy. Routledge.

Royal Commission on Aboriginal Peoples. (1996). Report of the Royal Commission on Aboriginal Peoples: Vol. 4. Perspectives and realities. https://wizard.unbc.ca/record=b1156379 S3

Sạn'yas Indigenous Cultural Safety Training. (n.d.). Sạn'yas: Indigenous Cultural Safety Training. https://www.sanyas.ca/training

Sayani, A. (2019). Health equity in national cancer control plans: An Analysis of the Ontario Cancer Plan. International Journal of Health Policy and Management, 8(9), 550-556. https://doi.org/10.15171/ijhpm.2019.40 
Schierhout, G., Hains, J., Si, D., Kennedy, C., Cox, R., Kwedza, R., O’Donoghue, L., Fittock, M., Brands, J., Lonergan, K., Dowden, M., \& Bailie, R. (2013). Evaluating the effectiveness of a multifaceted, multilevel continuous quality improvement program in primary health care: Developing a realist theory of change. Implementation Science, $8(1)$. https://doi.org/10.1186/1748-5908-8-119

Sinha, V., \& Kozlowski, A. (2013). The structure of Aboriginal child welfare in Canada. The International Indigenous Policy Journal, 4(2), 1-21. https://doi.org/10.18584/iipj.2013.4.2.2

Statistics Canada. (2019). Aboriginal Peoples highlight tables, 2016 Census. https://www12.statcan.gc.ca/census-recensement/2016/dp-pd/hlt-fst/aboaut/Table.cfm?Lang=Eng\& $\mathrm{S}=99 \& \mathrm{O}=\mathrm{A} \& \mathrm{RPP}=25$

Sukhera, J., Gonzalez, C., \& Watling, C. J. (2020). Implicit bias in health professions: From recognition to transformation. Academic Medicine, 95(5), 717-723. https://doi.org/10.1097/ $\underline{\text { ACM.0000000000003173 }}$

Tait, C. L. (2009). Disruptions in nature, disruptions in society: Aboriginal Peoples of Canada and the "making” of fetal alcohol syndrome. In L. J. Kirmayer \& G. G. Valaskakis (Eds.), Healing traditions: The mental health of Aboriginal Peoples in Canada (pp. 196-218). UBC Press.

Tang, S. Y., \& Browne, A. J. (2008). 'Race' matters: Racialization and egalitarian discourses involving Aboriginal people in the Canadian health care context. Ethnicity and Health, 13(2), 109-127. https://doi.org/10.1080/13557850701830307

Truth and Reconciliation Commission of Canada (TRC). (2015). Honouring the truth, reconciling for the future: Summary of the final report of the Truth and Reconciliation Commission of Canada. https://ehprnh2mwo3.exactdn.com/wp-content/uploads/2021/01/ Executive Summary English Web.pdf

Turpel-Lafond, M. E. (2020). In plain sight: Addressing Indigenous-specific racism and discrimination in B.C. health care. https://engage.gov.bc.ca/app/uploads/sites/613/2020/11/In-Plain-SightFull-Report.pdf

United Nations. (2016). State of the world's Indigenous Peoples: Vol. 2. Indigenous Peoples'access to health services. https://www.un-ilibrary.org/content/books/9789210575553

Vallianatos, M. A. (2018). Best approaches for anti-racist education. https://www.uvic.ca/equity/ education/anti-racism/index.php

van de Kleut, G. (2011). The Whiteness of literacy practice in Ontario. Race Ethnicity and Education, 14(5), 699-726. https://doi.org/10.1080/13613324.2011.585338

Varcoe, C. (2006). Doing participatory action research in a racist world. Western Journal of Nursing Research, 28(5), 525-540. https://doi.org/10.1177/0193945906287706

Varcoe, C., Brown, H., Calam, B., Harvey, T., \& Tallio, M. (2013). Help bring back the celebration of life: A community-based participatory study of rural Aboriginal women's maternity experiences 
and outcomes. BMC Pregnancy and Childbirth, 13(1), 26. https://doi.org/10.1186/1471$\underline{2393-13-26}$

Varcoe, C., Browne, A. J., \& Blanchet Garneau, A. (2019). Beyond stress and coping: The relevance of critical theoretical perspectives to conceptualising racial discrimination in health research. Health Sociology Review, 28(3), 245-260. https://doi.org/10.1080/14461242.2019.1642124

Varcoe, C., Browne, A. J., \& Kang, B. (2019). Culture and cultural safety: Beyond cultural inventories. In D. Gregory, C. Raymond-Seniuk, \& L. Patrick (Eds.), Canadian fundamentals of nursing $\left(2^{\text {nd }}\right.$ ed.). Lippincott Williams \& Wilkins.

Varcoe, C., Bungay, V., Browne, A. J., Wilson, E., Wathen, C. N., Kolar, K., Perrin, N., Comber, S., Garneau, A. B., Byres, D., Black, A., \& Price, R. (2019). EQUIP Emergency: Study protocol for an organizational intervention to promote equity in health care. BMC Health Services Research, 19(1), 687. https://doi.org/10.1186/s12913-019-4494-2

Varcoe, C., Ford-Gilboe, M., Browne, A. J., Perrin, N., Bungay, V., McKenzie, H., Smye, V., Price, R., Koushambhi, J. I., \& Dion Stout, M. (2019). The efficacy of a health promotion intervention for Indigenous women: Reclaiming our spirits. Journal of Interpersonal Violence. https://doi.org/10.1177/0886260518820818

Varcoe, C., \& McCormick, J. (2007). Racing around the classroom margins: Race, racism and teaching nursing. In L. Young \& B. Patterson (Eds.), Learning nursing: Student-centered theories, models, and strategies for nurse educators (pp. 439-446). Lippincott Williams \& Wilkins.

Vernon, R., \& Papps, E. (2015). Cultural safety and continuing competence. In D. Wepa (Ed.), Cultural safety in Aotearoa New Zealand ( $2^{\text {nd }}$ ed.). Cambridge University Press. https://doi.org/ $\underline{10.1017 / \mathrm{CBO} 9781316151136.007}$

Ward, C. (2018). Teaching about race and racism in the classroom: Managing the Indigenous elephant in the room [Doctoral dissertation, Simon Fraser University). Simon Fraser University Summit Institutional Repository. http://summit.sfu.ca/item/18705

Williams, D. R., Lawrence, J. A., \& Davis, B. A. (2019). Racism and health: Evidence and needed research. Annual Review of Public Health, 4O(1), 105-125. https://doi.org/10.1146/annurevpublhealth-040218-043750

Wrathall, D., Wilson, K., Rosenberg, M. W., Snyder, M., \& Barberstock, S. (2020). Long-term trends in health status and determinants of health among the off-reserve Indigenous population in Canada, 1991-2012. The Canadian Geographer / Le Géographe canadien, 64(2) 199-214. https://doi.org/10.1111/cag.12592

Wyatt, R., Laderman, M., Botwinick, L., Mate, K., \& Whittington, J. (2016). Achieving health equity: A guide for health care organizations. http://www.ihi.org/resources/Pages/IHIWhitePapers/ Achieving-Health-Equity.aspx 